\title{
Los crímenes y la extracción sin futuro: el caso de la explotación cauchera en el Putumayo (1880-1915)
}

\section{Crimes and the extraction without future: the case of the rubber exploitation in Putumayo (1880-1915)}

Jesús Franco Salazar Paiva ${ }^{1}$

Pontificia Universidad Católica del Perú

\section{Resumen}

¿La explotación del caucho fue vista realmente como una oportunidad para el desarrollo peruano a finales del siglo XIX y a comienzos del siglo XX? En el presente ensayo, se considera que hubo una percepción de oportunidad perdida tanto en el plano social como en el plano económico. En primer lugar, esta actividad económica se vio ensombrecida con las denuncias de crímenes atroces en contra de la población

1 Licenciado en Literatura, magíster en Historia, diplomático peruano. Correo electrónico: salazar.jesus@pucp.pe. Las ideas y opiniones vertidas en el presente ensayo son expresadas a título personal y no representan un punto de vista oficial por parte del Ministerio de Relaciones Exteriores del Perú. 
indígena en el Putumayo. La gravedad de los abusos puso en el debate público una reflexión sobre un sentido humano de civilización, frente a una manipulación de las teorías del darwinismo social que se emplearon para defender lo indefendible. En segundo lugar, la depredación de los recursos y la ausencia de una visión de futuro fueron otras variables que en su momento se advirtieron como taras para establecer un verdadero desarrollo. Todo ello configura dos dimensiones de la sensación de oportunidad perdida.

Palabras claves: caucho, crímenes, Putumayo, Peruvian Amazon Company, depredación, sostenibilidad, institucionalidad, actividad económica extractiva

\section{Abstract}

Was rubber exploitation really seen as an opportunity for Peruvian development at the end of the 19th century and at the beginning of the 20th century? In the present essay, it is considered that there was a perception of lost opportunity both in the social and in the economic plane. In the first place, this economic activity was overshadowed by the reports of atrocious crimes against the indigenous population in Putumayo. The seriousness of the abuses put into the public debate a reflection on a human sense of civilization, as opposed to a manipulation of the theories of social Darwinism that were used to defend the indefensible. Secondly, the depredation of resources and the absence of a vision of the future were other variables that at the time were perceived as defects to establish true development. This two dimensions shapes of the sensation of lost opportunity. 
Key words: rubber, crimes, Putumayo, Peruvian Amazon Company, depredation, sustainability, institutionality, extractive economic activity

\section{Introducción}

¿La explotación del caucho fue vista realmente como una oportunidad para el desarrollo peruano a finales del siglo XIX y a comienzos del siglo XX? Si se observa con más detalle los discursos producidos en torno a los atroces crímenes cometidos en contra de los indígenas del Putumayo y las voces que alertaban la depredación y la visión cortoplacista, se podrá observar que no fue un entusiasmo general el ver en esta actividad un ingreso del Perú a la modernidad y al desarrollo económico.

Para ello, el presente ensayo se centra en uno de los episodios más conocidos de la región amazónica: la explotación cauchera y los crímenes contra la población indígena del Putumayo. Para los años 1880 - 1915, esta región designaba un área mayor a la que puede aludir actualmente en el lector. Era un área muy amplia entre los actuales ríos Caquetá y Putumayo, entre lo que hoy en día es parte del sur de Colombia (departamentos de Amazonas y Putumayo) y el norte del Perú (región Loreto). ${ }^{2}$

2 La región del Putumayo no limitaba con la actual zona limítrofe bañada por el río Putumayo, sino con una vasta región comprendida entre el río Caquetá (actual Colombia) y regiones debajo de la actual frontera natural entre las dos repúblicas, en actual territorio peruano. De hecho, La Chorrera, una de las estaciones caucheras más importantes, se encontraba en actual territorio colombiano, al norte del río Putumayo. Hoy es una ciudad que pertenece políticamente al departamento de Amazonas (Colombia). 
En ese sentido, este ensayo aborda principalmente la huella de la actividad del empresario peruano Julio César Arana y los crímenes cometidos contra la población indígena por la empresa que dirgía, la Peruvian Amazon Company (PAC). $\mathrm{Al}$ analizar con más detalle, se observa como las reacciones ante las denuncias por los crímenes despiertan una decepción por parte del papel de la denominada "civilización" y pone en entredicho las concepciones del momento de conceptos como modernidad, nacionalismo, soberanía. En ese mismo análisis, la labor económica muestra rasgos similares: depredación y visión inmediata, sin conciencia de futuro. Por consiguiente, en el período señalado, la actividad extractiva del caucho se percibió como una oportunidad perdida. Luego, la Primera Guerra Mundial y el desarrollo de la explotación cauchera británica en sus colonias se encargarán de determinar el paulatino eclipse de esta labor.

Los crímenes del Putumayo ocurrieron en un periodo enturbiado por las incertidumbres de presiones externas y carencias internas para articular efectivamente la región a la nación. Aparte de las propias limitaciones geográficas y de conectividad, en el plano del debate, la creencia de un choque entre la civilización y la modernidad entendida como una imposición violenta de lo occidental, sustentada en discursos propios del darwinismo social- promovidas por los caucheros y sus defen-

90 sores- harán aún más difícil una real integración. Este aspecto será denunciado por otra corriente que contrapone la necesidad del imperio de la ley y la institucionalidad. Esta corriente será enarbolada por pocas voces denunciantes como Benjamín Saldaña Roca o los jueces Carlos Valcárcel y Rómulo Paredes.

En el plano económico, esta actividad mostraba signos de un deterioro progresivo por depredar los recursos materiales 
y humanos, $y$ al no establecer mecanismos para su mantenimiento, pese a existir competidores en el mercado mundial que amenazaban su hegemonía, como el desarrollo del caucho por parte de los ingleses en sus colonias asiáticas. La tala indiscriminada y los métodos rudimentarios para la extracción de los diversos tipos de caucho mostraban una limitada colonización y más bien una búsqueda de fortuna inmediata. No faltaron lugareños que trataron de plantar lo destruido y proponer métodos para una sostenibilidad de la actividad; sin embargo, no fueron voces mayoritarias, aunque sí tuvieron cabida en publicaciones oficiales.

Estos dos aspectos rescatados como enfoques de reflexión construyen una mirada que responde la pregunta inicial: la extracción del caucho, con sus consecuencias colaterales en el ámbito social y económico, representaron ya en su tiempo una oportunidad perdida para el desarrollo nacional.

\section{Los crímenes del Putumayo}

\subsection{La perspectiva cauchera y la defensa de su accionar: Julio C. Arana y el Putumayo}

Julio César Arana (1864-1952) es un personaje histórico que grafica el proceso de la región del Putumayo. En un principio, se había dedicado a la venta de sombreros en Yurimaguas, actividad comercial tradicional de la Amazonía. Desde sus inicios como comerciante, Arana fue un hombre inclinado a observar su entorno y aprovechar las circunstancias. Así, mientras vendía sombreros, conoció y comprendió el accionar de los aventureros que buscaban caucho (Lagos, 2005). 
En 1889, cuando ya Iquitos se posicionaba como un punto focal del comercio fluvial propiciado por el auge gomero, Arana se estableció en esa región para consolidar el trabajo que ya realizaba en ese rubro desde 1881 (Basadre, 1964, p. 3654). Iquitos fue el centro desde el cual se expandió hacia Manaos, punto clave del tránsito hacia el Atlántico y los países demandantes del caucho (Chirif y Cornejo, 2009, p. 18). A fines del siglo XIX, en 1897, Iquitos ya era la capital del departamento de Loreto (Contreras y Cueto, 2013, p. 225).

Sin embargo, el ascenso de Arana hasta convertirse en el empresario abanderado de esta actividad extractiva -aunque en extremo dependiente de los precios internacionales- no estuvo exento de choques con otros aventureros, especialmente colombianos. El proceso de ocupación del Putumayo por colonos caucheros estuvo marcado por imprecisiones. Los espacios no estaban delimitados con la precisión actual, sino que la abundancia reconocida en la zona del Putumayo estaba en gran parte a merced de diferentes aventureros no solo peruanos, sino también colombianos. Estos últimos ingresaron a la región atraídos primero por la explotación de la quina. Desde 1875 y 1880, los caucheros colombianos se establecieron en la región y aprovecharon el puerto de Iquitos como el punto de exportación del circuito extractivo (Villegas y Botero, 1979, p. 535). Arana

92 se enfrentó a ellos, los expulsó por la fuerza y reivindicó el repliegue de los extranjeros como una acción patriótica, aspecto enfatizado por sus defensores.

En una carta dirigida al presidente Augusto B. Leguía, fechada el 12 de junio de 1909, Julio César Arana lista seis puntos de las necesidades de la región y lo que el cauchero considera algunos aportes por parte de su empresa: 
$1^{\circ}$ Necesidad de no desalojar en forma violenta á los colombianos allí establecidos ó que merodeaban por esas latitudes; sino, al contrario, aprovecharlos en las primeras excursiones é ir seleccionando lentamente al personal, hasta reemplazarlo con elementos peruanos (Arana, 1909).

Ya para cuando escribe estas líneas, Arana se había convertido en el cauchero dominante de la región. Incluso su otrora socio Benjamín Larrañaga ya había muerto. No obstante, el cauchero opta por presentar una labor de pacificación y organización progresiva de la región para garantizar la peruanidad de la región. La idea era fundamentalmente garantizar una presencia y para entonces, con las limitaciones de la época, era aceptable - por no haber muchas opciones- que esta acción particular que garantizaba una presencia regular fuera un modo de desarrollar una política de protección de la soberanía nacional. En ese contexto, Arana aprovechó la ocasión para señalar que la labor patriótica de su empresa se condice con métodos pacíficos, aspecto que a todas luces no es cierto. Por otro lado, continúa en un segundo punto:

$2^{\circ}$ Calidad de bracero, que no era ni podía ser otro que el indio salvaje y antropófago, á quien necesitábamos reducir por medio de la persuasión, de la astucia y de la energía, debiendo advertirse que abundan las tribus belicosas y feroces (Arana, 1909).

En este punto destacado por Arana, se vislumbra uno de los aspectos más resaltantes de la defensa de los caucheros: la civilización de los indígenas, a quienes, según afirmaban, habían rescatado de formas primitivas de vida para insertarlos en una actividad económica "civilizada". Esta visión se enlaza con el siguiente punto, de acuerdo con la inversión en una zona alejada y sometida a toda clase de riesgos: 
$3^{\circ}$ Distancias enormes que recorrer por regiones donde jamás había existido un camino, cruzado una embarcación, ni cosechádose una sola planta doméstica, y donde, por lo tanto, se carecía en lo absoluto de víveres y viviendas (Arana, 1909).

Del mismo modo, Arana sentencia el poco sentido de la cordura y la racionalidad, y con ello busca aminorar su responsabilidad por los crímenes perpetrados por sus empleados, los cuales ya estaban saltando al debate público:

$4^{\circ}$ Imposibilidad de obtener empleados de cierta preparación y cordura, capaces de vigilar el trabajo de los indios por reducir y de afrontar los peligros y las privaciones de su cometido (Arana, 1909).

Explícitamente, Arana se manifiesta como un patriota y un empresario comprometido que, a través de la inversión, ha propiciado el inicio del desarrollo en una región inhóspita y apartada del país:

$5^{\circ}$ Inversión de fuertes capitales para adquisición de embarcaciones, apertura de caminos, edificación de casas, tambos, depósitos, etc., crianza de animales, formación de chacras, pastales, etc. (Arana, 1909).

El cauchero subraya esos lineamientos, incluso con las limitaciones que surgen de variables externas que dificultan

94 la acción de su empresa, aspecto que sumará a la dimensión nacional, identificando los riesgos de la compañía cauchera:

$6^{\circ}$ Resistencia opuesta por las autoridades y el gobierno del Brasil al paso de las mercaderías y productos de nuestro tráfico, en la parte brasilera del Iga ó Putumayo (Arana, 1909). 
Es evidente, el interés de Arana por presentar su accionar como un aspecto positivo en tanto garantiza una presencia. Su compromiso, desde su óptica, no solo se limita a resistir el embate de dos países vecinos con intereses políticos y económicos en la región, sino que también representan las bases de un progresivo desarrollo.

Las denuncias se publicaron primero en Iquitos. Valientemente, el periodista Benjamín Saldaña Roca denunció en 1907 los crímenes en sus periódicos La Felpa y La Sanción (Chirif y Cornejo, 2009, p. 19; Valcárcel, 2004, p. 344). Este fue el verdadero inicio de la búsqueda de justicia; sin embargo, las autoridades coludidas con la empresa cauchera impidieron que se realice un juicio y negaron la veracidad de los crímenes (Basadre, 1964, p. 3655).

Al comienzo de las denuncias, la explicación más a la mano era la carencia material de la región y el carácter indómito que torna a sus exploradores en una especie de héroes. Carlos Rey de Castro, Cónsul General del Perú en Manaos, señala lo siguiente en una carta dirigida al presidente José Pardo en 1908:

Hay personas que desearían haber encontrado en el $\mathrm{Pu}$ tumayo centros de población con todos los caracteres de la vida urbana, perfecta y definitivamente constituidos. Estoy seguro de que esto hará sonreír a vuecencia, preparado para el ejercicio del gobierno y que conoce cuales son los procesos de la evolución social (Rey de Castro, 1908, p. 6).

En ese entramado narrativo, la labor de Arana surge como un peldaño de visión evolutiva, basada en las ideas de civilización y barbarie que se defendían en esos momentos con 
pretensiones científicas. Sin embargo, el escándalo que provocarían los crímenes no tardaría en estallar, pues no obstante las pretensiones patrióticas de Arana y sus socios, el empresario cauchero optó por cobijar su empresa bajo la bandera británica. Fue precisamente esa condición británica la que propició la necesidad de investigar su accionar y la veracidad de las denuncias por parte de la sociedad civil inglesa y la opinión pública internacional, además de la política antiesclavista que promovía la potencia europea.

\subsection{El escándalo internacional del Putumayo y la respuesta de la justicia nacional}

Cuando la diplomacia británica y voces autorizadas (incluido el papa Pío X, por ejemplo) se pronunciaron por estas atrocidades denunciadas en semanarios y libros, surgió la figura del filántropo irlandés Roger Casement. ¿Cómo reaccionó la justicia peruana ante el contundente informe de este enviado especial de la Corona británica? Desafortunadamente, pese a sus recomendaciones y contundentes denuncias, no se castigó a los culpables o al menos no con el rigor que ameritaba la gravedad de sus delitos. La posibilidad de esa impunidad se debió a una sumatoria de factores, entre los cuales la ausencia institucional (de hecho, se conocía poco de la región y el aparato estatal era limitado) y la

96 colusión de algunas autoridades y personajes influyentes con poder de la empresa cauchera fueron los más evidentes. Sin embargo, en ese contexto de crisis, la conciencia moral de algunos peruanos fue la base de una apuesta por la legalidad, la institucionalidad y el respeto civilizado de los derechos de los demás. Dos de ellos - no es casual-fueron dos jueces que trataron de llevar al banquillo a los responsables de estos crímenes: Rómulo Paredes y Carlos Valcárcel. 
La recepción mediática de los crímenes puede ser leída en tres etapas en función del impacto producido, tanto en la acción de la justicia nacional e internacional como en las publicaciones a favor y en contra:

\section{a. Primera fase: la denuncia y primer intento de inves- tigación penal}

1900-1907: Denuncias diversas de exploradores y misioneros.

1907: Denuncia en la Corte Superior de Iquitos formulada por el periodista Benjamín Saldaña Roca (publicación de las denuncias en La Felpa y La Sanción de Iquitos, y reproducidas en El Comercio de Lima).

1908-1910: Investigaciones que niegan la existencia de los crímenes.

b. Segunda fase: la primera visita de Roger Casement y el proceso judicial del Putumayo

1910: Primera visita de Roger Casement al Putumayo.

1911: Denuncias episódicas en la prensa internacional.

1911: El juez Carlos Valcárcel acoge la denuncia de la Fiscalía Superior de Iquitos.

1911: Ante la enfermedad de Valcárcel, Rómulo Paredes, juez suplente, viaja al Putumayo. Presentó dos informes en los que confirmó la veracidad de las denuncias.

1911: Valcárcel ordena detener a altos directivos de la Peruvian Amazon Company.

1912: Segunda visita de Roger Casement. 


\section{c. Tercera fase: la guerra impresa y la condena moral}

1913: El Libro azul británico, publicación del Foreign Office de Inglaterra y publicado también por el Congreso de los Estados Unidos de América.

1913: Valcárcel publica en Panamá Los crímenes del Putumayo.

1913: El libro rojo del Putumayo, publicación colombiana.

1913-1914: Publicaciones defensoras de los caucheros: Carlos Rey de Castro y otros personajes vinculados a la Peruvian Amazon Company.

1915: Valcárcel reedita su libro de 1913 con el título de El proceso del Putumayo y sus secretos inauditos.

El impacto mediático fue el más contundente. La batalla decisiva que permitió la intervención de variables externas que se impusieron al poder omnímodo de los caucheros de la Peruvian Amazon Company en la región muestra indicios de cómo fue creciendo la opinión pública nacional e internacional y cómo fue un factor de peso en la búsqueda de justicia y de un marco de respeto por la legalidad.

El entonces cónsul británico en Río de Janeiro fue enviado en 1910 al Perú para investigar las denuncias sobre horrendos crímenes contra los indígenas -especialmente boras y huitotos- perpetrados por empleados de la compañía cauchera Peruvian Amazon Company en el Putumayo. El hecho de que el cónsul británico investigara propició un quiebre notorio en la búsqueda de la justicia, pues antes no se habían realizado esfuerzos por hallar a los criminales ni sancionar a 
los culpables. ${ }^{3}$ Fue, por lo tanto, una variable interviniente que, externamente, impactó en una idiosincrasia caracterizada por la carencia, la lejanía del centro administrativo y el accionar neutralizador de la empresa cauchera que señoreaba en el Putumayo.

En Inglaterra, tanto las denuncias de Saldaña Roca como las de Casement fueron divulgadas en un semanario llamado Truth, el cual había acogido las denuncias del ingeniero estadounidense Walter Handerburg ${ }^{4}$ en 1909, quien había estado en la zona de asentamiento de la empresa cauchera y había sido testigo de los atropellos y crímenes cometidos por los agentes de la compañía, además de haber sido él víctima de abusos.

De este modo, no solo la presencia de capitales británicos, sino sobre todo el involucramiento de súbditos de la Corona en estos crímenes (por un lado, había capataces de Barbados, parte del Imperio británico en aquellos tiempos, y, por otro, socios ingleses de reputación respetable) conmovió a la opinión pública inglesa (y luego internacional) y movilizó a la sociedad civil, especialmente a la Sociedad Antiesclavista de Londres. En ese contexto, Casement -ya famoso por su demoledor informe de denuncia de los crímenes en el Congo de Leopoldo II- fue enviado al Perú para esclarecer estos

3 Jorge Basadre señala que ya habían existido denuncias esporádicas que mostraban las atrocidades de los caucheros en el Putumayo. La mayoría provenía de misioneros católicos hasta que Saldaña Roca denunció los crímenes.

4 En 1912, Handerburg publicó un compendio de su testimonio y otras denuncias sobre los crímenes del Putumayo en el libro titulado Putumayo, The Devil's Paradise. Su libro reproduce y dialoga con el informe de Roger Casement. 
escandalosos crímenes y ver el estado y tratamiento de los súbditos ingleses en la región (Barclay, 2012).

El informe de Roger Casement no solo confirmó la veracidad de las denuncias, sino que ahondó en aspectos relevantes para el análisis de estos crímenes en un polémico contexto: los despiadados métodos de tortura y el escaso control que el Estado peruano podía ejercer efectivamente en la región (Casement, 2011, pp. 35, 39, 41). Las apreciaciones de Casement tuvieron una especial resonancia por el contexto en el que se inscriben, pues confluyeron muchos factores: en principio, la visión humanitaria inglesa y su afán de aclarar el involucramiento de súbditos y capitales de su país; luego, la disputa limítrofe entre el Perú y Colombia por la zona del Putumayo, aspecto que motivó la versión de que Arana y sus empleados defendían el interés nacional; y el nuevo frente de competencia comercial que se instauraba con el éxito de las plantaciones británicas en el Lejano Oriente aspecto que, aunque secundario, pudo haber motivado algunos intereses que se sumaron al legítimo y humanitario deseo de aclarar la verdad y de hacer justicia. ${ }^{5}$ (Salazar, 2014, p. 60). De hecho, como señala Chirif (2012a), lo que realmente permitió el cese de los abusos y crímenes fue efectivamente este último impacto: la pérdida de interés por el mercado natural de gomas del Putumayo, precisamente por el surgimiento de la

5 Alberto Chirif señala que Inglaterra no necesitaba escándalos para tumbar la competencia comercial de las gomas silvestres del Putumayo, pues solo representaba el $6.2 \%$ de las gomas que se consumían en ese momento y su aparato industrial era mucho más sofisticado (2012b, p. 23). No obstante esta documentada precisión, no es imposible que algún interés contrario al auge comercial de la empresa de Arana pudiera haber influido o sumado presión en el accionar de la potencia europea. 
alternativa exportadora de las colonias inglesas. Sin embargo, fue devastador para el negacionismo promovido por los caucheros la publicación del informe de Casement con el título Libro azul británico (1912) por el impacto internacional de las denuncias. ${ }^{6}$

La labor de Casement, por lo tanto, se vio comentada desde estas aristas que polarizaron las reacciones. Por su parte, los caucheros de la Peruvian Amazon Company enfatizaron el mencionado argumento de la defensa de la soberanía nacional ante la amenaza de la invasión colombiana al ser una contención en términos prácticos. Se declararon civilizadores de una inhóspita región. Acusaron de un favoritismo antiperuano a las observaciones de Casement y de un marcado interés procolombiano. Uno de los más fervientes defensores de Arana fue el ya mencionado Carlos Rey de Castro, cónsul del Perú en Manaos (Brasil). ${ }^{7}$ En 1913, al renunciar a su cargo consular, se dedicó a la defensa de Arana a través de libros en los que esgrime este tipo de ideas, además de basarse en la eugenesia y la pretendida superioridad evolutiva del hombre blanco y occidental sobre la "barbarie" de los indígenas del

6 El Libro azul, como apunta Chirif en su estudio introductorio del libro (Chirif, 2012b, p. 8), fue editado por Inglaterra en 1912 y en él se presenta cómo la Corona británica comunica al Gobierno de los Estados Unidos de América la decisión de publicar estos informes ante la falta de sanción de los culpables.

7 En el contexto de Iquitos de comienzos del siglo XX, Manaos era el primer contacto que tenía con los beneficios del mundo exterior. Antes de llegar a Iquitos, se pasaba por Manaos. Cuando había carestía de abarrotes o medicinas, Manaos era el punto de abastecimiento obligado. De ahí que el papel de coordinación que tuviera Carlos Rey de Castro fuera de importancia para la Peruvian Amazon Company. Esto se puede deducir de los propios informes de Rey de Castro (Rey de Castro, 1907-1913). 
Putumayo (Rey de Castro, 1913, 1914). Sin embargo, no se podía justificar ni ocultar la veracidad ni la gravedad de las atrocidades perpetradas. El único camino que quedaba a los caucheros era el ataque personal contra quienes osaban retar su poder y cumplían su deber como lo hicieron los jueces Rómulo Paredes y Carlos Valcárcel, quienes además actuaban en un contexto limitado para el accionar de la justicia.

Cuando en 1907 Benjamín Saldaña Roca denunció las atrocidades perpetradas impunemente en el Putumayo, recién se había creado la Corte Superior de Iquitos (Valcárcel, 2004, p. 60). La falta de una Corte había impedido que antes se pudiera denunciar a los criminales; sin embargo, la denuncia solo le traería problemas y hostilidad a Saldaña Roca. Se trató de negar su patriotismo al acusarlo de trabajar para los intereses colombianos y de ser un hombre mezquino que no reconocía el bien que promovía Julio César Arana en Iquitos. No obstante los ataques, la denuncia tuvo eco en Lima y las autoridades ordenaron una investigación, cuyos resultados negaron la veracidad de los hechos. El juez Valcárcel considera que esta acción fue la más grande manifestación de anhelo de justicia de Iquitos (Valcárcel, 2004, pp. 89-90). Luego de este intento, la labor de Roger Casement reactivó un segundo momento en la búsqueda del esclarecimiento de los crímenes, esta vez con el juez disponible para atenderlos:

102 Carlos Valcárcel.

Sin embargo, cuando Valcárcel tomó a su cargo la investigación en 1911, ni la voluntad de esclarecimiento había crecido ni los obstáculos desaparecieron. Uno de los primeros aspectos del cual el juez se percató es que lo que había motivado que el fiscal superior de Iquitos, Salvador Cavero, presentase la denuncia de los crímenes era fundamentalmente el 
escándalo mediático. El fiscal había manifestado la urgencia de atender las denuncias, porque había leído cómo personalidades del mundo intelectual y periodístico estaban denunciando y confirmando la veracidad de los hechos (Valcárcel, 2004, pp. 98-99). Es decir, solo cuando los crímenes habían devenido en escándalos internacionales adicionales a los estallados en Inglaterra, se tomó la decisión de investigar, aspecto que indignó al magistrado por evidenciar una crisis en el accionar de la justicia. Desde que se reactivó el caso, el juez tuvo que afrontar obstáculos, por ejemplo, no recibía viáticos para su viaje al Putumayo, supuestamente por carecer de una orden desde Lima para ello, además de la hostilidad diaria en las calles de la capital loretana (Valcárcel, 2004, p. 102). Posteriormente, se enfermó, por lo que tuvo que ir a Nueva York para tratarse. ${ }^{8}$ En ese contexto, la Corte de Iquitos designó al juez Rómulo Paredes para que investigara las denuncias en el mismo terreno de los hechos. La razón de esa elección era que el juez Paredes tenía la condición de suplente (Valcárcel, 2004, p. 103).

El juez Rómulo Paredes llegó a Iquitos y visitó el Putumayo. Verificó in situ que las denuncias no solo eran ciertas, sino que además nada se había hecho para resolver ni reparar los dańos provocados por los caucheros de la empresa de Arana. Como fruto de su viaje, el juez Paredes redactó dos informes ${ }^{9}$ dirigidos a Germán Leguía y Melén-

8 Dado el problema de la incomunicación geográfica entre Lima e Iquitos, era más fácil para un viajero ir a los Estados Unidos o Europa que llegar a la capital de la República.

9 Alberto Chirif y Manuel Cornejo aportan significativamente a los estudios históricos del tema al haber reproducido los informes en una obra que compila ensayos sobre los crímenes del Putumayo (Chirif y Cornejo, 2009). 
dez, Ministro de Relaciones Exteriores del Perú. Estos informes revelan -además de la veracidad señalada- cómo los caucheros se esmeraban para generar en Paredes una perversa imagen del indígena, presentándolo como antropófago, inmoral, salvaje y violento, treta en la que Paredes no cayó y que, más bien, denunció (Chirif y Cornejo, 2009, pp. 75-100). Paredes mostró con ello un gran coraje frente a la presión de Arana y sustentó como hombre de leyes la necesidad de aplicar justicia sin prejuicios ni excusas. Tuvo que convivir con la acechanza y el temor a un atentado. Nada lo detuvo y estuvo dispuesto a llevar el tema hasta sus últimas consecuencias.

Poco antes del retorno de Paredes del Putumayo a Iquitos, Valcárcel retornó de Nueva York y al volver consideró estratégicamente más apropiado emplear los trabajos de su colega y basarse en los mismos para abrir el proceso contra los penalmente responsables, puesto que consideró que de no hacerlo así podría involuntariamente anular el esfuerzo realizado por el magistrado y brindarle argumentos a los defensores legales y políticos de los caucheros para desestimar el valor de la investigación de Rómulo Paredes. De esta manera, al retornar Paredes, Valcárcel ordenó, basado en sus informaciones, la detención de Pablo Zumaeta, cuñado de Arana, quien además era gerente general de la Peruvian Amazon Company, 104 además de otros directivos de la empresa bajo el cargo de encubridores de los asesinos (Valcárcel, 2004, p. 107). A raíz de esta decisión, el juez tuvo que enfrentar las acusaciones -incluso penales- contra él. Desafortunadamente, poco después fue separado del caso y tuvo que partir de Iquitos, soportar amenazas de muerte, intentos de asesinato y obstáculos logísticos y administrativos. 
Valcárcel, felizmente, sobrevivió al cargamontón y al hostigamiento cotidiano. Desafortunadamente, los culpables no pudieron ser llevados al banquillo de los acusados. Impunemente, como retrata la novela de Vargas Llosa, muchos de los criminales escaparon al extranjero o a Lima. Sin embargo, a pesar de que la acción de justicia no alcanzó a los criminales, otro acto de justicia sí se impuso decididamente por obra directa de Valcárcel.

Alejado del proceso judicial y ante el temor de que estos hechos quedaran sin sanción, el juez Valcárcel previó la necesidad de que en el futuro no pueda vencer la impunidad del olvido ni que se pueda decir que los crímenes del Putumayo jamás ocurrieron y que, por ende, careciera de la sanción moral de la mirada histórica. Por ello, publicó en Panamá el libro titulado Los crímenes del Putumayo (1913).

En Los crímenes, el autor representa un comentario de los expedientes de las denuncias y reflexiones sobre aspectos relacionados con la necesidad de aplicar justicia. Las denuncias y la descripción detallada de las atrocidades quedaron consignadas por escrito y ante la mirada de la opinión pública internacional. No pudieron callar a Valcárcel y su deseo firme de contribuir a la construcción de un mejor país a través del imperio de la ley y de la justicia. Fue un golpe que no se esperaban los defensores decididos de Arana y sus cómplices. La perspectiva desde la que presenta los hechos es la del amargo sabor de la derrota de los procedimientos, pero con la satisfacción de haber cumplido con el deber hasta el final y con la esperanza de la sanción social para los culpables y para la reflexión de la ciudadanía. 
Dos años después, en Lima, reeditó su obra con un título distinto, El proceso del Putumayo y sus secretos inauditos (1915) en la que hizo algunos agregados a la edición de 1913. Para empezar, es interesante notar el cambio del título. Se evidencia una nueva percepción de Valcárcel respecto del proceso; ya no se enfatiza la necesidad de reconocer que lo acaecido en el $\mathrm{Pu}$ tumayo fueron crímenes ni tampoco se habla de la actualidad del proceso, más bien, es necesario desentrañar los secretos inauditos del frustrado intento de juzgar a los criminales (Salazar, 2014, p. 117). Su público es la posteridad y su legado es un mensaje que no pierde vigencia por ser parte de la historia del Perú y de las lecciones que debe aprender de la misma.

Esta obra puede ser considerada como un antecedente de la búsqueda de la verdad y de una sincera defensa de la imagen del Perú, convenientemente asociada a los intereses de los caucheros acusados. Valcárcel es enfático al señalar que podrían existir funcionarios y hombres poderosos coludidos con Arana, pero ello no implicaba que debiera relacionarse el nombre de la patria con estos crímenes ni con sus perpetradores, por lo que la acción de la justicia no solo era urgente por cuestiones morales, sino también porque estaba en juego el prestigio del Perú ante los ojos del mundo.

\section{La actividad extractiva del caucho en el Putumayo} (1880-1912): las perspectivas irracionales y racionales de la actividad económica

\subsection{Aspectos generales de la actividad cauchera}

La actividad extractiva del caucho fue el resultado de una demanda internacional intensa en el contexto de la Revo- 
lución Industrial. El progresivo avance de las gomas hizo que la cifra de producción se incrementara de "aproximadamente 400 toneladas en 1850 a 50 000-60 000 toneladas en $1900 \ldots$ La producción de las áreas dedicadas al caucho continuó expandiéndose hasta 1912, en que se alcanzó una producción récord de 70000 toneladas", aunque poco después de ese año, los precios comenzaron un franco declive debido al apogeo de las gomas inglesas producidas en sus colonias en el Lejano Oriente (Thorp y Bertram, 2013, p. 96).

Hasta el año 1912, el caucho proveniente del Perú era uno de los rubros más destacados en la actividad económica peruana por sus cifras de exportación, las cuales debido al buen precio sostenido hasta entonces generaban considerables ganancias. Para tener algunas nociones al respecto, se presentan algunos testimonios.

En 1904, Eduardo Higginson, Cónsul General del Perú en Nueva York, escribió un artículo en el Boletín del Ministerio de Fomento del Perú en el que reflexiona sobre el porvenir de las exportaciones peruanas. El diplomático peruano señala que para entonces el precio de la libra de caucho peruano oscilaba entre $\$ 1.15$ y $\$ 1.20$, negocio que en un periodo muy breve puede generar ganancias considerables, lo que despierta crecientemente el interés de inversionistas extranjeros (Higginson, 1904, pp. 64, 67-68).

Un evento clave para su consolidación como actividad económica a gran escala fue el desarrollo de la industria automotriz:

Las razones de la importancia del caucho a comienzos de siglo [siglo XX] y los buenos precios estaba ligados a la na- 
ciente industria automotriz que requería este producto para la fabricación de las llantas; además de que las condiciones de esta inmensa zona eran favorables, la explotación del caucho era rentable en ese momento, a pesar de las dificultades de transporte, debido a dos razones: primero, que la única manera de obtenerlo era a través de los árboles, pues aún no se había logrado su producción sintética, y en segundo lugar y sobre todo, porque se contaba con mano de obra gratis (Villegas y Botero, 1979, p. 531).

Es decir, la demanda externa, aspecto conocido en la historia peruana, generó el auge de una actividad primaria basada en la exportación. Asimismo, como señala la cita, se trataba de un rubro que requería poco capital. La lógica de esta actividad económica fue fundamentalmente la extracción directa de la planta y, en consecuencia, la depredación de los distintos árboles gomeros.

Por otra parte, dentro de esta aparente facilidad del medio para el desarrollo del trabajo extractivo, desafortunadamente se invirtió también en un aparato represivo que garantizó la labor de la mano de obra esclava de los indígenas de la región y la seguridad de los campamentos de los caucheros y centros de acopio de la recolección, lo que propició la "cultura del terror" como denomina Michael Taussig a la maquinaria represiva de la PAC (Taussig, 1987).

\subsection{Las perspectivas para establecer una actividad extractiva sólida}

En 1909, en el Boletín del Ministerio de Fomento del Perú, José Armando Méndez, un investigador del derrotero de la explotación cauchera, publicó en un artículo que de “ 1885 hasta 1897 , fué el valle del Ucayali el centro principal de 
la producción del caucho" (p. 72). Sin embargo, es tanta la riqueza natural de las gomas de la región amazónica que agrega, citando un estudio:

No hace muchos ańos, casi todo el caucho venía del territorio peruano y era principalmente exportado por el puerto de Iquitos, ya directamente, bien por intermedio de las plazas de Manaos y Belem. Casi todos los afluentes del Amazonas han suministrado caucho; la extracción comenzó en 1882, aproximadamente, por los afluentes mayores del río Marañón, principalmente el Tigre, Morona, Pastaza, etc. (Méndez, 1909, p. 72).

En un artículo boliviano reproducido a modo de ejemplo en los albores del siglo XX en el Boletín del Ministerio de Fomento del Perú, se puntualizó el contraste de la pródiga presencia del recurso con sus limitaciones: "Las $\mathrm{Mi}$ candras, Manihots, Castilloas, Ficurs, Vahéas, Landolphas, Urceola, Harconias, etc., etc. reemplazarán en Bolivia, el salitre, el guano y borateras... Empero esta positiva ventaja que reportaría la nación es obstruida por la falta casi absoluta de caminos que anula el incremento de la industria gumífera" (Jordán, 1903, p. 1). Como señalaban Villegas y Botero en una cita anterior, dadas las condiciones geográficas, los aspectos que necesitaban mayor inversión eran, precisamente, el acceso y el transporte por los ríos de regiones poco exploradas y distantes de los centros de poder político y económico. ${ }^{10}$

10 Un ejemplo de esta logística es que en muchas de las investigaciones realizadas para esclarecer las denuncias por el Gobierno peruano y la diplomacia británica, las embarcaciones empleadas para viajar por los ríos de la región eran de propiedad de la PAC. 
Este estudio es particularmente ilustrativo, ya que menciona con claridad las maneras como se realizaba la extracción en la época. Señala dos métodos principales: el derribo de los árboles y la sangría, pica o escisión (Jordán, 1903, p. 4).

En el texto, el autor calibra las consecuencias de ambas prácticas y, tomando en cuenta una visión de largo plazo, nota la evidente ausencia de un criterio de sostenibilidad de la actividad económica y, por ello, la considera una actitud "bárbara" e "irracional", puesto que:

rinde provecho inmediato, pero por una sola vez; la naturaleza después de muchos años de labor, habrá puesto á merced del hombre un recurso de trabajo y de provecho, y de un solo golpe de hacha esta penosa preparación queda aniquilada y será necesario el nuevo transcurso de otro largo espacio de tiempo para reparar el dańo que la imprevisión, la incuria y la indolencia del recolector unidas á su ambición hubieran destruido (Jordán, 1903, p. 5).

En relación con la sangría o pica, Jordán entiende como una actividad mucho más responsable si se realiza con el adecuado cuidado para no matar al árbol ni afectar la calidad de la goma y por ello la considera "racional" (p. 6). El autor subraya la necesidad de optar por este método como un modo serio de desarrollar productivamente una actividad con miras a un desarrollo que pueda mantenerse. Adicionalmente, detalla que en países vecinos como Brasil están llevando a cabo con éxito esta práctica, aunque requiere una mayor sofisticación porque le resta calidad. Por otra parte, sugieren un método más cuidadoso en el que, con el empleo de una soga alrededor del tronco, se genera una barrera para que el líquido de la goma caiga en los recipientes y las impurezas se queden en la soga (p. 7). 
En 1908, Serafín Filomeno presenta una alarmada visión del poco desarrollo del caucho como actividad económica:

Hablando con propiedad en Loreto solo hai una industria que es el tejido ó manufactura del sombrero de paja, que principió para Moyobamba i para el Perú el año 27.

Toma su materia prima de una palmera de origen loretano, que no se cultiva i sólo se atiene á a los productos espontáneos.

Esta industria necesita que se cultive la paja, que se mejore su beneficio i que la forma del sombrero sea adaptable á las variaciones i exigencias de la moda. Así, en los últimos cuatro años que ha tomado la forma de "Cuba Libre" ó de "Chicago", ha obtenido mayor precio i mayor consumo.

El caucho ó la goma elástica, en general, no es en Loreto una industria, ni siquiera embrionaria como las anteriores; es llana i simplemente la destrucción de la riqueza natural, en provecho de unos cuantos especuladores, sin miras económicas, sin patriotismo i sobre todo sin conciencia. (Filomeno, 1908, p. 3).

Es destacable que la irresponsabilidad y el desinterés de aquellos que se dedican a la actividad extractiva solo depredando no son patriotas, porque no construyen nada, aspecto claramente en oposición de la autopercepción de los caucheros de Arana. Por otra parte, Filomeno expresa los puntos del circuito económico, desde la presencia de un cultivo que sostiene el porvenir de una industria hasta la venta, como fruto de un trabajo denodado, no como un facilismo que no llega a nada. Lamentablemente, nunca fue escuchado, como él mismo señala. 
Para la posteridad, quedan algunas de sus denuncias de esa tendencia destructiva de la actividad extractiva:

No puede ser una industria una explotación en la que se corta á más i mejor los árboles para obtener la mayor cantidad de resina en el menor tiempo posible. Desde el principio de la explotación de la goma en 1882 hasta la fecha, se han destruido 200,000,000 de árboles, es haciendo el cálculo más reducido. Es preciso estar en los bosques al pié de esos ávidos destructores de los bosques para ver cómo se les destroza i convencerse de que este cálculo es verdadero.

En vista de esta destrucción, que dará por resultado el agotamiento del caucho i de todas las plantas gomeras i que ha producido sus efectos perniciosos, á tal punto que ahora hai que buscarlo en regiones más lejanas, indiqué por repetidas veces desde 1890 á los representantes de Loreto la necesidad de cultivar el caucho para reponer las plantas que se destruían tan temerariamente, sin lograr ser escuchado jamás (Filomeno, 1908, p. 3).

Sugiriendo un paralelismo final, las voces solitarias que pedían una visión constructiva de la industria cauchera quedaron aplacadas por la vorágine extractiva, como los que apostaron por la legalidad y fueron amenazados por la impunidad de los criminales y su poder corruptor. El eje destructivo unifica estos planos de la problemática en torno a los crímenes del Putumayo y el ocaso de una crisis que generó un caso más

112 de prosperidad efímera.

\section{Reflexiones finales}

En el presente ensayo, se ha querido esbozar como la actividad cauchera representó un entusiasmo inicial para el desarrollo del país. Sin embargo, no tardaron las denuncias en los 
planos social, jurídico y económico, los cuales manifestaron una percepción de este importante momento de la región amazónica como una oportunidad perdida para el desarrollo nacional.

Los defensores de los caucheros consideraban, desde una óptica evolutiva y con el difícil control de una región alejada y de difícil acceso, que la presencia y la penetración arriesgada eran un peldaño evolutivo en el camino a la consolidación futura de una colonización peruana que tenía como paso previo indispensable la progresiva expulsión de los caucheros y exploradores colombianos. En ese sentido, impusieron su presencia y su accionar en la región del Putumayo como un comienzo progresivo, sin ser capaces de entender la precariedad en la que ellos mismos se sumergían por invertir en aspectos extractivos (medios de transporte y herramientas rudimentarias) y no en aquello que permitiera una visión de futuro para la actividad económica. Por ello, esta actividad no construyó una base social para el desarrollo económico, puesto que "el cauchero no fue colonizador, sino trashumante" (Flores, 1987, p. 27). Ello influyó también en la ausencia de otras industrias y en el consumo de bienes externos (Rumrill, 1980, pp. 4-5). De esta manera, la violencia y el terror impuestos en la región se condicen con la depredación cortoplacista e irresponsable que caracterizó la acción cauchera y son las expresiones de una misma carencia que impidió un verdadero desarrollo.

Es importante destacar, para finalizar, que este episodio de la historia del Perú manifiesta un entramado de relaciones sociales y económicas de una idiosincrasia particular que amerita una profundización (por ejemplo, los detalles de 
la colonización, la libre navegación, la relación Manaos - Iquitos, entre otros). Estas reflexiones darían muchas luces para entender más completamente la historia contemporánea del Perú, gracias a una más detallada reflexión sobre la historia amazónica.

Recibido: 11 de agosto del 2018.

Aprobado: 18 de diciembre del 2018.

\section{Bibliografía}

\section{Fuentes primarias}

Arana, J. C.

(1909) Carta dirigida al Ministerio de Relaciones Exteriores del Perú. 12 de junio de 1909. Archivo de Límites del Ministerio de Relaciones Exteriores del Perú. (Código LEK -13-3).

Filomeno, S.

Apuntes sobre el caucho. Serafín Filomeno de Moyobamba. En C. Larrabure y Correa, Colección de leyes, decretos, resoluciones y otros documentos oficiales referentes al departamento de Loreto. 1905-1909. Lima.

Higginson, E.

(1904). El porvenir de los mercados de los productos peruanos. Boletín del Ministerio de Fomento, 2(10).

114 Jordán, N.

(1903) Extracción y beneficio de la goma elástica. Boletín del Ministerio de Fomento, 1 (10).

Méndez, J. A.

La producción del caucho. Boletín de la Dirección de Fomento (8).

Orihuela, T.

(1910) Informe sobre las compañías de plantaciones de caucho. Boletin del Ministerio de Fomento, 8(6). 
Rey de Castro, C.

(1908) Carta dirigida a don José Pardo. 30 de junio de 1908. Archivo de Límites del Ministerio de Relaciones Exteriores del Perú. (Código LEK -13-1).

Rey de Castro, C.

(1913) Los escándalos del Putumayo. Carta abierta dirigida a Mr. Geo Mitchell, cónsul de su Majestad Británica. Barcelona: Viuda de Tasso.

Rey de Castro, C.

(1907-1913) Informes consulares. Lima: Archivo Central del Ministerio de Relaciones Exteriores del Perú.

Rey de Castro, C.

(1914) Los pobladores del Putumayo. Origen y nacionalidad. Barcelona: Viuda de Tasso.

Valcárcel, C.

(2004) El proceso del Putumayo y sus secretos inauditos. Iquitos: Monumenta Amazónica.

\section{Fuentes secundarias}

Barclay, F.

(2012) Tras 100 años los pueblos del Putumayo no han sido reparados, de palabra ni de obra. Recuperado de https:// www.servindi.org/actualidad/62825

Basadre, J.

(1964) Historia de la República del Perú (t. VII-VIII). Lima: Banco Central de Reserva del Perú.

Casement, R.

(2011) Libro azul británico. Informes de Roger Casement y otras cartas sobre las atrocidades del Putumayo. Lima: Centro Amazónico de Antropología y Aplicación Práctica (CAAAP). Recuperado de https://centroderecursos.cultura.pe/sites/default/files/rb/pdf/ Libro\%20Azul\%20Britanico.pdf 
Chirif, A.

(2012a) Explotación del caucho y traslado de la población indigena. Recuperado de https://www.servindi.org/actualidad/73555

Chirif, A.

(2012b) El auge del caucho o el juego de las apariencias. En

R. Casement, Libro azul británico. Informes de Roger Casement y otras cartas sobre las atrocidades del Putumayo. Lima: Centro Amazónico de Antropología y Aplicación Práctica (CAAAP). Recuperado de https://centroderecursos.cultura.pe/sites/default/files/rb/pdf/Libro\%20Azul\%20Britanico.pdf

Chirif, A. y Cornejo, M.

(2009) Imaginario e imágenes de la época del caucho. Los sucesos del Putumayo. Lima: Centro Amazónico de Antropología y Aplicación Práctica.

Contreras, C. y Cueto, M.

(2013) Historia del Perú contemporáneo. Lima: Instituto de Estudios Peruanos.

Flores, J.

(1987) La explotación del caucho en el Perú. Lima: UNMSM.

García Jordán, P.

(2005) La Cueva, la Liga y el escándalo del Putumayo. Organización social y representación política en Iquitos (Loreto) en los inicios del siglo XX. En A. Gutiérrez, Estudios sobre América XVI - XX. Sevilla: AEA.

116 (2005)

Arana, rey del caucho. Iquitos: Tierra Nueva.

Rumrill, R.

El puerto libre o el fracaso del modelo liberacionista importador en la Amazonia peruana. Folleto del Coloquio Sobre la Nueva Conquista de la Selva desarrollado en Pucallpa. Lima: Centro de Documentación del CAAAP. 
Salazar, J.

(2014) El proyecto nacional ensangrentado: nacionalismo y civilización en torno a los discursos de los crimenes de la Peruvian Amazon Company en el Putumayo (Tesis para optar por el título de Magíster en Historia). Pontificia Universidad Católica del Perú, Escuela de Posgrado, Lima.

Taussig, M.

(1987) Cultura del terror, espacio de la muerte: el informe del Putumayo de Roger Casement y la explicación de la tortura. Amazonía Peruana, 8 (14).

Thorp, R. y Bertram, G.

(2013) Perú 1890-1977. Crecimiento y políticas en una economía abierta. Lima: Universidad del Pacífico.

Villegas, J. y Botero, F.

(1979) Putumayo, indígenas, caucho y sangre. Cuadernos Colombianos, t. III. 
